\title{
Prokinetic effects of LD02GIFRO on functional gastrointestinal disorder in rats
}

\author{
MYUNG-JOO CHOI ${ }^{1 *}$, HONG-MEI ZHENG ${ }^{1 *}$, HEE DONG PARK ${ }^{2}$, \\ HEE KYUNG JEONG ${ }^{2}$, SOON-SUN HONG ${ }^{1}$, JAE MIN KIM ${ }^{3}$ and DON HAENG LEE ${ }^{1,3,4}$ \\ ${ }^{1}$ Department of New Drug Development, College of Medicine, Inha University, Incheon 22332; \\ ${ }^{2}$ LG Life Sciences, Ltd., R\&D Center, Yuseong-gu, Daejeon 34122; \\ ${ }^{3}$ National Centre of Efficacy Evaluation for The Development of Health Products; \\ ${ }^{4}$ Division of Gastroenterology \& Hepatology, Inha University Hospital, Jung-gu, Incheon 22332, Republic of Korea
}

Received October 1, 2015; Accepted November 18, 2016

DOI: $10.3892 / \mathrm{etm} .2017 .4185$

\begin{abstract}
LD02GIFRO is a novel prokinetic agent formulated with Poncirus fructus and Zanthoxylum sp. fruits. The aim of the present study was to evaluate the effect of LD02GIFRO on delayed gastrointestinal transit (GIT) and colorectal hypersensitivity. To investigate the effect of LD02GIFRO, a rat model of delayed GIT was induced via three mechanisms; postoperative ileus (POI), morphine, and POI plus morphine. Visceromotor responses (VMR) to colorectal distension (CRD) were also evaluated. POI was induced by laparotomy surgery and manipulation of the small intestine under anesthesia, and GIT was calculated by measuring the length that Evans Blue travelled through the gastrointestinal tract in a given time. Oral administration of $260 \mathrm{mg} / \mathrm{kg}$ LD02GIFRO caused Evans Blue to migrate significantly further in the delayed GIT models induced by POI, morphine and POI plus morphine compared with the control $(\mathrm{P}<0.05)$. This effect was inhibited by atropine, a muscarinic receptor antagonist, and completely abolished by GR125487, a 5-HT 4 -receptor antagonist. Furthermore, intraperitoneal administration of 600 and $900 \mathrm{mg} / \mathrm{kg}$ LD02GIFRO significantly reduced VMR to CRD in acute and chronic colorectal hypersensitive rat models, induced by acetic acid and trinitrobenzenesulfonic acid, to almost normal levels $(\mathrm{P}<0.01)$. In the present study, LD02GIFRO successfully ameliorated delayed GIT models and colorectal hypersensitivity models, suggesting that LD02GIFRO may be an effective therapeutic treatment for patients with functional gastrointestinal disorders and abnormalities in GIT.
\end{abstract}

Correspondence to: Professor Don Haeng Lee, Department of New Drug Development College of Medicine, Inha University, 3-ga, Sinheung dong, Jung-gu, Incheon 22332, Republic of Korea

E-mail: 1dh@inha.ac.kr

${ }^{*}$ Contributed equally

Key words: prokinetic, gastrointestinal transit, colorectal hypersensitivity, LD02GIFRO

\section{Introduction}

Functional gastrointestinal disorder (FGID) is one of the most common gastrointestinal disorders in humans, encompassing functional dyspepsia and irritable bowel syndrome (IBS) (1). The pathophysiology of FGID is complicated and there are various factors to consider, including abnormal motility, visceral hypersensitivity, psychological factors, and disturbed brain-gut interaction (1). Disturbed digestive motility is often responsible for the manifestation of gastrointestinal symptoms in various diseases (2).

Postoperative ileus (POI) typically occurs following abdominal surgery and is characterized by a transient hypomotility of the gastrointestine, which may prolong hospital stays and increase mortality $(3,4)$. Surgical stress stimulates the release of endogenous opioids, resulting in impaired post-surgical gastrointestinal function $(5,6)$. Previous studies have suggested $\mu$-opioid receptor antagonists, cholinergic agonists or 5- $\mathrm{HT}_{4}$ receptor agonists as targets for the development of a drug to improve management of POI $(7,8)$.

IBS is considered to be a functional gastrointestinal disorder characterized by chronic abdominal pain and discomfort associated with alteration in bowel habits in the absence of demonstrable pathology (9). Evidence suggests that increased visceral sensitivity is primarily responsible for the manifestation of symptoms of IBS (10). At present, it has been suggested that abnormal interactions between normal and disordered motility or visceral hypersensitivity may be responsible for IBS symptoms $(11,12)$.

Prokinetic drugs are commonly prescribed for gastrointestinal disorders in humans (13). However, two gastroprokinetic agents, domperidone and tegaserod, are associated with serious side effects $(14,15)$, and the efficacy data on two others, mosapride and itopride, are conflicting $(16,17)$. Therefore, there is a requirement for safer and more effective gastroprokinetic agents to be developed. LD02GIFRO is a novel prokinetic agent obtained from extracts of Poncirus fructus (PF) and Zanthoxylum sp. fruits (ZF), both of which have been used in Asian traditional medicine for the treatment of gastrointestinal disorders. PF has been used as a traditional medicine for the treatment of abnormal gastrointestinal motility and gastric 
secretion (18-20). ZF, which belongs to the Rutaceae family, has been used as a traditional medicine to alleviate stomach pain, diarrhea, and jaundice (21,22). Additionally, ZF extracts have been demonstrated to have a prokinetic effect that is able to ameliorate delayed gastrointestinal transit (GIT) in rats, and have been reported to stimulate duodenal and ileal motility $(23,24)$. Based on these traditional herbal medicinal theories and clinical records, PF and ZF were selected for use in the present study.

\section{Materials and methods}

Preparation of LD02GIFRO. LD02GIFRO is the standardized extract of two herbs. PF is the immature fruit of Poncirus trifoliate, and Zanthoxyli fructus is the pericarp of Zanthoxylum piperitum. These herbs were purchased at a Chinese herb medicine shop in Kyung-dong Market (Seoul, South Korea) and washed with distilled water to remove adulterations prior to use. A total of $100 \mathrm{~g}$ of dried Poncirifructus was added to $800 \mathrm{ml}$ of $70 \%$ ethanol and $250 \mathrm{~g}$ of dried Zanthoxyli fructus was added to $1,750 \mathrm{ml}$ of $30 \%$ ethanol. The herbs were subsequently extracted at room temperature for $24 \mathrm{~h}$, concentrated at $55-65^{\circ} \mathrm{C}$ under $25.5 \mathrm{MPa}$ pressure and dried to obtain the solvent extracts of Ponciri fructus and Zanthoxyli fructus. The $70 \%$ ethanol extract of Ponciri fructus and 30\% ethanol extract of Zanthoxyli fructus were mixed at a ratio of 1:12 by weight to prepare the complex extracts of Ponciri fructus and Zanthoxyli fructus.

Chemicals. Atropine sulfate, mosapride, phenol red, Evans Blue and trinitrobenzenesulfonic acid (TNBS) were purchased from Sigma-Aldrich (Merck Millipore, Darmstadt, Germany). Acetic acid was purchased from Junsei Chemical Co., Ltd. (Tokyo, Japan). Alvimopan and morphine were purchased from GlaxoSmithKline PLC (Brentford, UK) and BC World Pharm Co., Ltd. (Seoul, Korea), respectively. GR125487 was purchased from Tocris Bioscience (Bristol, UK).

Experimental animals. A total of 296 male Sprague-Dawley rats (age, 6 weeks; weight, 180-200 g) were obtained from Orient Bio, Inc. (Gyeonggi, Korea). Animal care and experimental procedures were conducted in accordance with the approval and guidelines of the Institutional Animal Care and Use Committee of the Medical School of Inha University (Incheon, Korea; approval ID, INHA 140618-302, INHA 141126-340). Rats were provided standard rat chow and tap water ad libitum and were maintained at room temperature $\left(25-30^{\circ} \mathrm{C}\right)$ and at $45-55 \%$ relative humidity in a 12 -h light/dark cycle. Rats were fasted for $24 \mathrm{~h}$ prior to experiments, with ad libitum access to water. Rats were randomly distributed into experimental groups (37 groups; $n=8$ per group).

Surgical preparation. Rats were anesthetized via intraperitoneal injection of $100 \mathrm{mg} / \mathrm{kg}$ ketamine (Yuhan Co., Ltd., Seoul, Korea) and $4.4 \mathrm{mg} / \mathrm{kg}$ xylazine (Bayer AG, Leverkusen, Germany). Teflon-coated electrodes (A-M Systems, Inc., Sequim, WA, USA) were implanted in the external oblique muscles and externalized to the back of the neck to record electromyography (EMG). The experiment was initiated three days post-surgery.
POI. POI was induced according to the previously reported method (25). Control and treatment groups were anesthetized with 3\% isoflurane (Hana Pharm Co., Ltd., Seoul, Korea) and the abdomen was opened via a $2-\mathrm{cm}$ midline laparotomy. The small intestine and caecum were gently pulled out of the abdominal cavity and the small intestine was gently manipulated with the fingers for $5 \mathrm{~min}$. Following manipulation, the small intestine and caecum were replaced in the abdominal cavity, and the surgical wound was sutured. The normal group underwent isoflurane anesthesia only.

GIT. To study the effects of POI on GIT, $0.2 \mathrm{ml}$ Evans Blue $(50 \mathrm{mg} / \mathrm{ml})$ in saline was orally administered to each rat $4 \mathrm{~h}$ post-operatively. Rats ( $\mathrm{n}=8$ per group) were sacrificed under $100 \mathrm{mg} / \mathrm{kg}$ ketamine (Yuhan Co., Ltd.) and $4.4 \mathrm{mg} / \mathrm{kg}$ xylazine (Bayer AG) anesthesia $20 \mathrm{~min}$ after the administration of Evans Blue, and the rate of GIT was calculated by dividing the distance of Evans Blue migration by the total length of the small intestine.

Study 1: In the POI model group, LD02GIFRO $(65,130$ or $260 \mathrm{mg} / \mathrm{kg})$ or alvimopan $(10 \mathrm{mg} / \mathrm{kg})$ was orally administered $30 \mathrm{~min}$ prior to Evans Blue. Control and normal rats were orally administered the same volume $(5 \mathrm{ml} / \mathrm{kg})$ of vehicle $(5 \%$ Pluronic F-68; Sigma-Aldrich; Merck Millipore). Rats were randomly distributed into six groups ( $n=8$ per group): Normal group, $3 \%$ isoflurane anesthesia + vehicle; control group, POI + vehicle; LD02GIFRO groups $(65,130$ or $260 \mathrm{mg} / \mathrm{kg}), \mathrm{POI}+$ LD02GIFRO; and alvimopan group, POI + alvimopan.

Study 2: To investigate whether LD02GIFRO was able to ameliorate delayed GIT induced by morphine $(3 \mathrm{mg} / \mathrm{kg})$, LD02GIFRO was administered $30 \mathrm{~min}$ after a subcutaneous (s.c.) injection of morphine (3 mg/kg; BC World Pharm Co., Ltd.). Rats were randomly distributed into six groups $(n=8$ per group): Normal group, $3 \%$ isoflurane anesthesia + vehicle; control group, POI + vehicle; LD02GIFRO groups $(65,130$ and $260 \mathrm{mg} / \mathrm{kg}$ ), POI + LD02GIFRO; and alvimopan group, POI + alvimopan.

Study 3: As presurgical treatment, LD02GIFRO was administered $30 \mathrm{~min}$ prior to morphine ( $1 \mathrm{mg} / \mathrm{kg}$, s.c.), which was in turn administered 15 min prior to the intestinal manipulation to induce POI. Two h post-surgery, Evans Blue was orally administered, and rats were deeply anesthetized 20 min later under $100 \mathrm{mg} / \mathrm{kg}$ ketamine (Yuhan Co., Ltd.) and $4.4 \mathrm{mg} / \mathrm{kg}$ xylazine (Bayer AG) anesthesia. Subsequently, the abdominal aorta was transected to exsanguinate the rats. Rats were randomly distributed into five groups ( $\mathrm{n}=8$ per group): Normal group, 3\% isoflurane anesthesia + vehicle; control group: vehicle + morphine + POI; LD02GIFRO groups (130 and $260 \mathrm{mg} / \mathrm{kg}$ ): LD02GIFRO + morphine + POI; and alvimopan group, alvimopan + morphine + POI.

Study 4: As postsurgical treatment, morphine ( $1 \mathrm{mg} / \mathrm{kg}$, s.c.) was administered 15 min prior to POI surgery, and LD02GIFRO was administered 30 min post-surgery. At $2 \mathrm{~h}$ following the induction of POI, rats were administered with Evans Blue by gavage, and were sacrificed 20 min later. Rats were randomly distributed into five groups ( $n=8$ per group): Normal group, $3 \%$ 
isoflurane anesthesia + vehicle; control group, morphine + POI + vehicle; LD02GIFRO groups (130 and $260 \mathrm{mg} / \mathrm{kg}$ ), morphine + POI + LD02GIFRO; and alvimopan group, morphine + POI + alvimopan.

Study 5: To investigate whether cholinergic or serotonergic receptors mediate the stimulatory effect of LD02GIFRO on POI, rats were administered with saline $(1 \mathrm{ml} / \mathrm{kg})$, atropine $\left(2 \mathrm{mg} / \mathrm{kg}\right.$ ) or GR125487 (a 5- $\mathrm{HT}_{4}$ receptor antagonist; $2 \mathrm{mg} / \mathrm{kg}$ ) via s.c. injection $15 \mathrm{~min}$ prior to LD02GIFRO administration. The group that underwent both surgical and morphine treatment was designed to mimic the clinical situation of patients receiving opioids following abdominal surgery. Rats were randomly distributed into five groups $(n=8$ per group): Normal group, $3 \%$ isoflurane anesthesia + saline + vehicle; control group, POI + saline + vehicle; saline group, POI + saline + LD02GIFRO; atropine group: POI + atropine + LD02GIFRO; and GR125487 group, POI + GR125487 + LD02GIFRO.

Visceromotor responses (VMR) to colorectal distension $(C R D)$. Rats were anesthetized with $3 \%$ isoflurane and a barostat balloon (Mui Scientific, Mississauga, ON, Canada) was subsequently inserted into the distal colon and held in place by taping the balloon catheter to the base of the tail. The catheter was attached to a programmable rigid piston barostat with zero intrinsic compliance (Distender Series II; G\&J Electronics, Inc., Toronto, ON, Canada). The Teflon coated silver wire was connected to an alternating current (AC) amplifier system (Grass Instrument Co., West Warwick, RI, USA). The $\mathrm{AC}$ amplifier was connected to data acquisition equipment and data were analyzed using Powerlab 8/35 (PL3508; AD Instruments, Colorado Springs, CO, USA). The rats were left for $30 \mathrm{~min}$ to recover completely. The stimulus-response of the external oblique muscle during CRD was recorded with computerized signals in the holding cage. The CRD procedure consisted of two series of CRDs for $3 \mathrm{~min}$ at constant pressures of 15, 30, 45, 60 and $80 \mathrm{mmHg}$, separated by 3-min intervals without distension. The stimulus-response during each distension period was expressed as the integral.

Colonic hypersensitivity. Study 6: Acute colonic hypersensitivity was induced as described by Langlois et al (26) and Plourde et al (27). Briefly, male SD rats (300-400 g) were fasted overnight, anesthetized with $3 \%$ isoflurane and administered with an intracolonic infusion of dilute acetic acid $(0.6 \%$; $1.5 \mathrm{ml})$. Rats were randomly distributed into five groups $(\mathrm{n}=8$, each group): $0.6 \%$ AA group (0.6\% acetic acid + vehicle), $0.6 \%$ AA + LD02GIFRO groups $(300,600,900 \mathrm{mg} / \mathrm{kg})$; Normal control group: saline + vehicle.

Study 7: Chronic hypersensitivity was induced as described by Greenwood et al (28). Briefly, male SD rats (180-200 g) were anesthetized with $3 \%$ isoflurane and administered with an intracolonic infusion of TNBS $(50 \mathrm{mg} / \mathrm{kg} ; 0.5 \mathrm{ml}$ in $25 \%$ ethanol). The experiment was initiated 30 days after infusion. Rats were randomly distributed into five groups $(n=8$, each group): $50 \mathrm{mg} / \mathrm{kg}$ TNBS group (50 mg/kg TNBS + vehicle), $50 \mathrm{mg} / \mathrm{kg}$ TNBS + LD02GIFRO groups $(300,600,900 \mathrm{mg} / \mathrm{kg})$; Normal control group: $25 \%$ ethanol + vehicle.
Experimental design and drug treatment of colonic hypersensitivity. Experiments were designed to examine the effect of LD02GIFRO on acute acetic acid-induced colonic sensitivity and postinflammatory rat models. The VMRs to an initial series of CRDs were recorded $10 \mathrm{~min}$ prior to the administration of LD02GIFRO or the vehicle. A second series of CRDs was performed $10 \mathrm{~min}$ after intraperitoneal administration of LD02GIFRO $(300,600$ or $900 \mathrm{mg} / \mathrm{kg})$ or vehicle $(50 \%$ propylene glycol) and the VMRs recorded.

Data analysis and statistics. All values are expressed as the mean \pm standard error of the mean. Differences among groups were examined using a Mann-Whitney $\mathrm{U}$ test. $\mathrm{P}<0.05$ was considered to indicate a statistically significant difference. Data analyses were performed using SPSS software (version 19.0; IBM SPSS, Armonk, NY, USA). Abdominal muscular contractions in response to CRD, were monitored via EMG recording to determine the response to visceral pain. The degree of EMG response was positively correlated to the CRD volume. The EMG response was calculated as follows: Integral of EMG activity during CRD/80 mmHg control EMG response $\mathrm{x} 100$. Responses were measured for two consecutive series of CRD at 15, 30, 45, 60 and $80 \mathrm{mmHg}$.

\section{Results}

Effects of LDOIGIFRO on GIT. The aim of the present study was to investigate whether LD02GIFRO was capable of restoring delayed GIT. The rate of GIT was significantly reduced in rats post-surgery $(\mathrm{P}<0.01)$; however, administration of $\geq 65 \mathrm{mg} / \mathrm{kg}$ LD02GIFRO was able to ameliorate the delayed GIT, and a significant improvement was observed in the rats treated with $260 \mathrm{mg} / \mathrm{kg}(\mathrm{P}<0.05$; Fig. 1A). Furthermore, administration of $10 \mathrm{mg} / \mathrm{kg}$ morphine significantly decreased the GIT compared with the normal group $(\mathrm{P}<0.05)$. The maximum effect was presented at the dose of $260 \mathrm{mg} / \mathrm{kg}$, with GIT of $60.7 \pm 3.5 \%$ $(\mathrm{P}<0.05$; Fig. 1B). These results suggest that LD02GIFRO is able to accelerate GIT in rats with delayed GIT induced by laparotomy and morphine administration.

Pre-treatmentwith LD02GIFROformorphine and POIinduced delayed GIT. Rats were administered with LD02GIFRO $30 \mathrm{~min}$ prior to $1 \mathrm{mg} / \mathrm{kg}$ morphine injection ( $1 \mathrm{mg} / \mathrm{kg}$, s.c.), which was administered $15 \mathrm{~min}$ prior to mechanical stimulation. GIT was significantly decreased in the control group with presurgical treatment for vehicle and morphine rats (Fig. 1C; $\mathrm{P}<0.01$ ). However, administration of LD02GIFRO increased GIT by $32.7 \pm 9.3$ and $30.2 \pm 5.7 \%$ at the doses of 130 and $260 \mathrm{mg} / \mathrm{kg}$, respectively. Notably, treatment with $260 \mathrm{mg} / \mathrm{kg}$ LD02GIFRO significantly restored delayed GIT $(\mathrm{P}<0.01)$, whereas $10 \mathrm{mg} / \mathrm{kg}$ alvimopan had no significant effect on GIT.

Post-treatment with LD02GIFRO for morphine and POI induced delayed GIT. Rats were treated with $1 \mathrm{mg} / \mathrm{kg}$ morphine 15 min prior to surgery and LD02GIFRO was administered 45 min post-surgery. As demonstrated in Fig. 1D, GIT was significantly diminished in the control rats $(30.5 \pm 3.3 \%$; $\mathrm{P}<0.01$ ); however, LD02GIFRO significantly improved GIT at the dose of $260 \mathrm{mg} / \mathrm{kg}$ compared with the controls $(\mathrm{P}<0.05)$. Treatment with alvimopan also induced a significant increase 

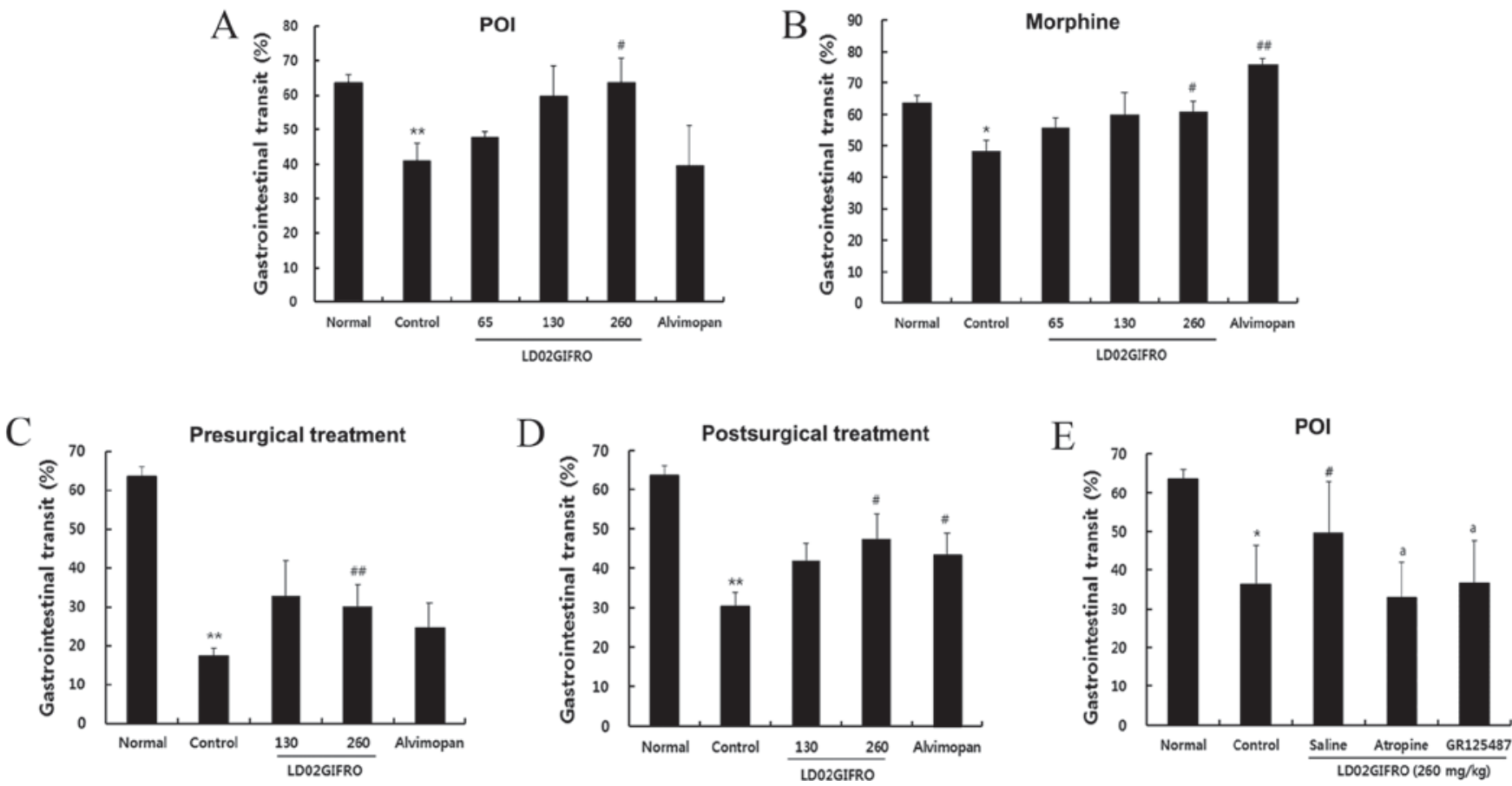

Figure 1. Effects of LD02GIFRO on GIT in rats. Following $24 \mathrm{~h}$ fasting, rats ( $\mathrm{n}=8$ each group) were orally administered with LD02GIFRO at indicated doses in combination with the following; alvimopan (10 mg/kg), atropine (2 mg/kg), GR125487 (2 mg/kg) and 5\% Pluronic F-68 as a vehicle (control). GIT in (A) POI-induced rats, (B) morphine-induced rats, (C) in presurgical treatment with morphine rats, (D) in postsurgical treatment with morphine rats, and (E) in POI-induced rats with atropine and GR 125487 treatment. Values are expressed as the mean \pm standard error of the mean. ${ }^{*} \mathrm{P}<0.05$ and ${ }^{* *} \mathrm{P}<0.01$ vs. normal group. ${ }^{\#} \mathrm{P}<0.05$ and ${ }^{\# \#} \mathrm{P}<0.01$ vs. control group ${ }^{a} \mathrm{P}<0.05$ vs. saline control group. GIT, gastrointestinal transit; POI, post-operative ileus.

in GIT rate compared with the controls $(\mathrm{P}<0.05)$. As a result of these findings, all subsequent experiments were performed using LD02GIFRO at a dosage of $260 \mathrm{mg} / \mathrm{kg}$.

Influence of atropine and GR125487 on the effect of LDO2GIFRO on delayed GIT in POI. GIT was markedly delayed in rats with $\mathrm{POI}$ compared with normal rats $(\mathrm{P}<0.05$; Fig. 1E). Administration of $260 \mathrm{mg} / \mathrm{kg}$ LD02GIFRO significantly ameliorated the delayed GIT $(\mathrm{P}<0.05)$; however, this amelioration was prevented by co-administration of $2 \mathrm{mg} / \mathrm{kg}$ atropine, a muscarine-receptor antagonist $(32.9 \pm 9.1 \% ; \mathrm{P}<0.05)$ or GR125487 $(2 \mathrm{mg} / \mathrm{kg})$, a $5-\mathrm{HT}_{4}$ receptor antagonist $(49.2 \pm 5.7 \% ; \mathrm{P}<0.05)$.

Effects of LD02GIFRO in rats with acute colonic hypersensitivity. Acute colonic hypersensitivity in rats induced by intra-colorectal infusion of $0.6 \%$ acetic acid was assessed by comparing the exaggerated VMR to graded pressure of CRD with the control rats (Fig. 2A-C). Rats with acute colonic hypersensitivity developed significant visceral hyperalgesia compared with the control group $(\mathrm{P}<0.01)$; this hypersensitivity was evident for all CRD pressures (Fig. 2C). To investigate whether LD02GIFRO had an inhibitory effect on the VMR in rats with hypersensitivity to colonic stimulation, the rats were treated with LD02GIFRO $(300,600$ or $900 \mathrm{mg} / \mathrm{kg})$. The vehicle for LD02GIFRO, propylene glycol, had no significant effect on the VMR of acetic acid-treated rats (Fig. 2A). In contrast, when rats were administered with LD02GIFRO, the VMR level decreased in a dose-dependent manner. Rats treated with $300 \mathrm{mg} / \mathrm{kg}$, LD02GIFRO had a significantly lower VMR at CRD of $80 \mathrm{mmHg}$ compared with the acetic acid-treated response $(\mathrm{P}<0.05)$. At doses of $600 \mathrm{mg} / \mathrm{kg}$ the VMR was significantly reduced at all CRD pressures to a level similar to the corresponding control rats $(\mathrm{P}<0.01)$. Notably, the highest dose of $900 \mathrm{mg} / \mathrm{kg}$ induced a significantly greater reduction in VMR level at all distension pressures, with responses being reduced below the VMR level recorded in normal control rats $(\mathrm{P}<0.01$; Fig. 2C). Fig. 2B demonstrates a representative EMG response during the distension period to pressures from $15-80 \mathrm{mmHg}$ of vehicle, acetic acid-induced and following LD02GIFRO.

Effects of LD02GIFRO in rats with postinflammatory colonic hypersensitivity. It was investigated whether postinflammatory colonic hypersensitivity may be verified by recording electrical activity in response to CRD in rats (Fig. 3A-C). Rats developed significant visceral hyperalgesia compared with the control 30 days following the induction of TNBS colitis $(\mathrm{P}<0.01$; Fig. 3C). Hypersensitive rats were treated with LD02GIFRO or vehicle. The vehicle had no significant effect on the VMR at any CRD pressures (Fig. 3A), whereas LD02GIFRO (300, 600 or $900 \mathrm{mg} / \mathrm{kg}$ ) suppressed the VMR levels. At a dosage of 600 or $900 \mathrm{mg} / \mathrm{kg}$, the VMR induced by all distension pressures were significantly reduced to a VMR level below or similar to that recorded at pressures in normal control rats $(\mathrm{P}<0.01$; Fig. 3C). A representative EMG response to pressures from 15 to $80 \mathrm{mmHg}$ during a distension period in each treatment group is displayed in Fig. 3B.

\section{Discussion}

FGID is one of the most prevalent gastrointestinal disorders in humans (1). Several herbal medicinal products have been 

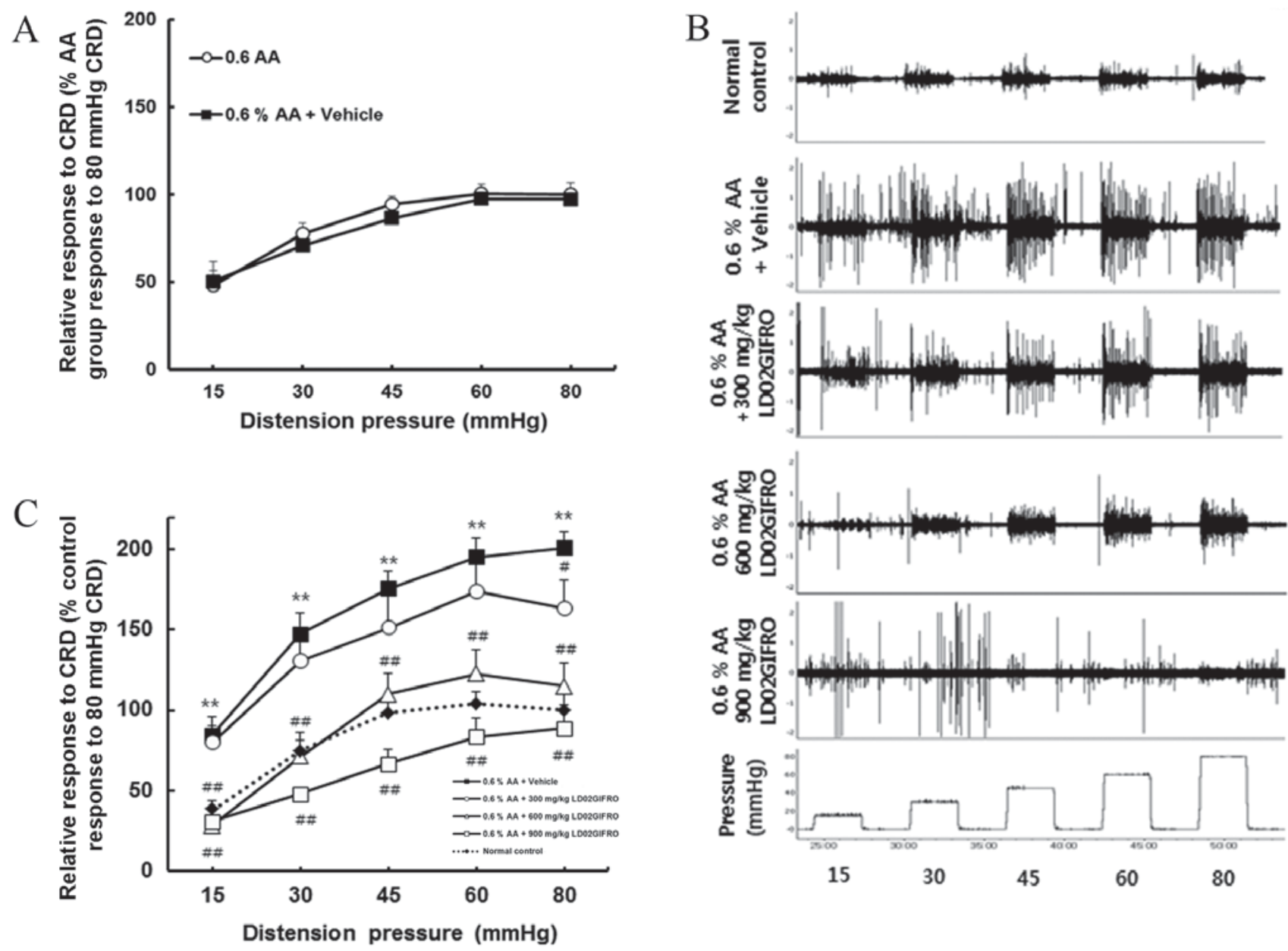

Figure 2. Effect of LD02GIFRO on VMR to CRD in rats with acute hypersensitivity. (A) VMR to CRD in rats with 0 AA-induced colonic hypersensitivity $(\mathrm{n}=8)$. (B) VMR to CRD represented electromyography. Values are presented as the mean \pm standard error of the mean. (C) Effect of LD02GIFRO on VMR to $\mathrm{CRD}$ in rats with AA-induced colonic hypersensitivity $(\mathrm{n}=8)$. ${ }^{* *} \mathrm{P}<0.01$ vs. normal control. ${ }^{*} \mathrm{P}<0.05$ and ${ }^{\# \#} \mathrm{P}<0.01$ vs. $0.6 \%$ AA plus vehicle. VMR, visceromotor response; CRD, colorectal distension; PG, propylene glycol; AA, acetic acid.

assessed to determine whether they may be used as an effective therapeutic treatment for patients with FGID (29). For example, a Chinese herbal medicine, known as Rikkunshi-to and TJ-43, has been reported to enhance gastric emptying (30) and gastric adaptive relaxation (31). It has been demonstrated that daikenchuto, a Japanese herbal medicine comprised of four herbs, is able to ameliorate morphine-induced inhibition of intestinal and colonic transit (32). However, the optimal therapeutic strategy for FGID remains to be determined due to the poorly defined pathogenesis of the condition. In the present study, the prokinetic agent LD02GIFRO was developed and its pharmacological effects evaluated. The results suggest that LD02GIFRO may have a prominent effect on gastrointestinal motility by ameliorating GIT and reducing visceral hypersensitivity.

Various mechanisms have been proposed for the pathogenesis of POI, although there is not yet a clear consensus. Experimental and clinical ileus has been demonstrated to be associated with the degree of surgical manipulation performed (33), suggesting that surgical manipulation of the intestine serves an important role in mediating POI $(34,35)$. Additionally, a typical factor that contributes to post-surgical gastrointestinal dysregulation is the use of opioids for pain management during the peri- and post-operative periods (36). Typically, morphine inhibits relaxation of the circular muscle and contraction of the longitudinal muscle, resulting in delayed GIT (37). In the present study, treatment with $260 \mathrm{mg} / \mathrm{kg}$ LD02GIFRO was demonstrated to significantly improve POI-induced delayed GIT. Morphine-induced delayed GIT was also eliminated by administration of $260 \mathrm{mg} / \mathrm{kg}$ LD02GIFRO.

Differences in the stimulatory effect were observed between pre- and post-treatment of LD02GIFRO with morphine and POI. GIT significantly improved with pre- and post-treatment of LD02GIFRO, whereas administration of alvimopan had a significant effect only when POI was accompanied with morphine.

Neural reflex pathways have previously been implicated in postoperative dysmotility; cholinergic agonists and $5-\mathrm{HT}_{4}$ receptor agonists are able to ameliorate postoperative GIT dysmotility $(7,38)$, suggesting that activation of the cholinergic nervous system or 5- $\mathrm{HT}_{4}$ receptor agonist improves dysmotility in POI. LD02GIFRO ameliorated the hypoperistalsis from POI, which was completely inhibited by treatment with atropine or GR125487. Therefore, the cholinergic nerves and 5- $\mathrm{HT}_{4}$ receptors may be involved in this action of LD02GIFRO. Based on these results, LD02GIFRO may be suggested as a superior treatment to conventional therapeutics, particularly for GIT in abnormal conditions. 

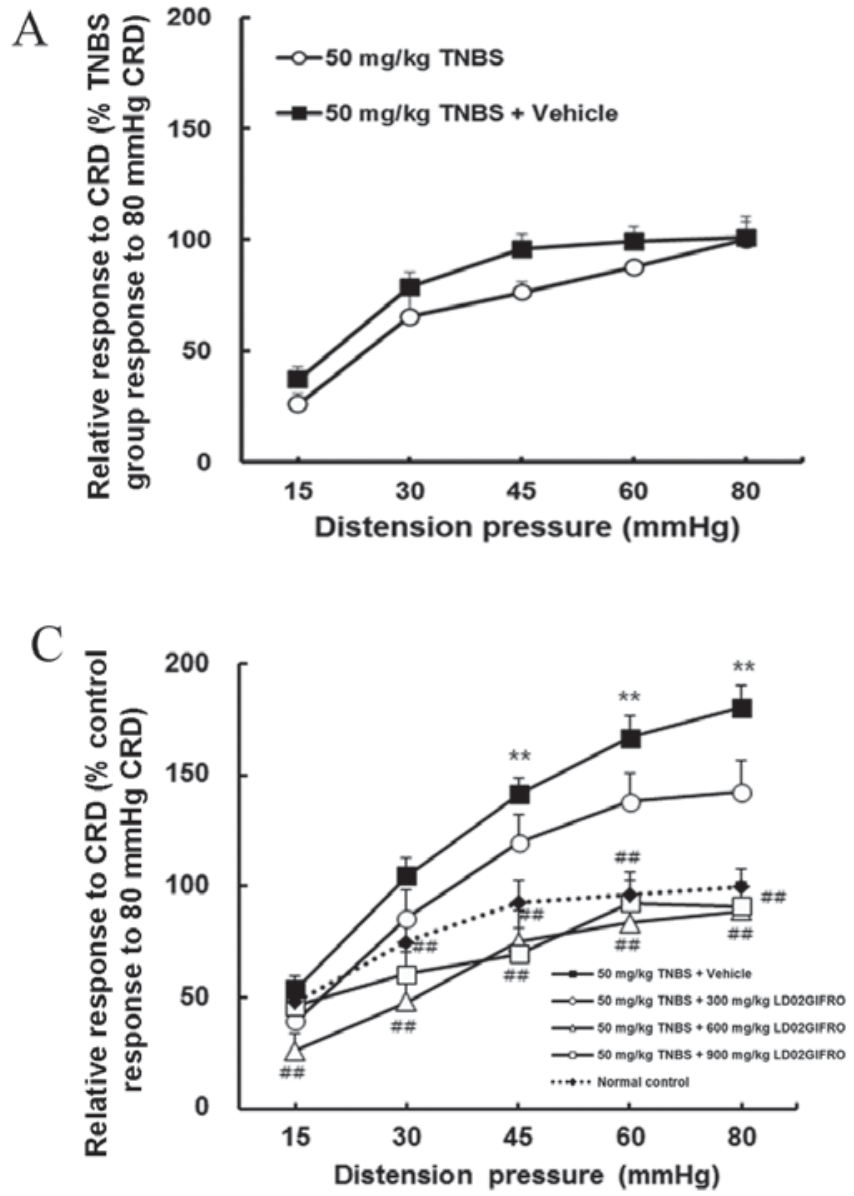

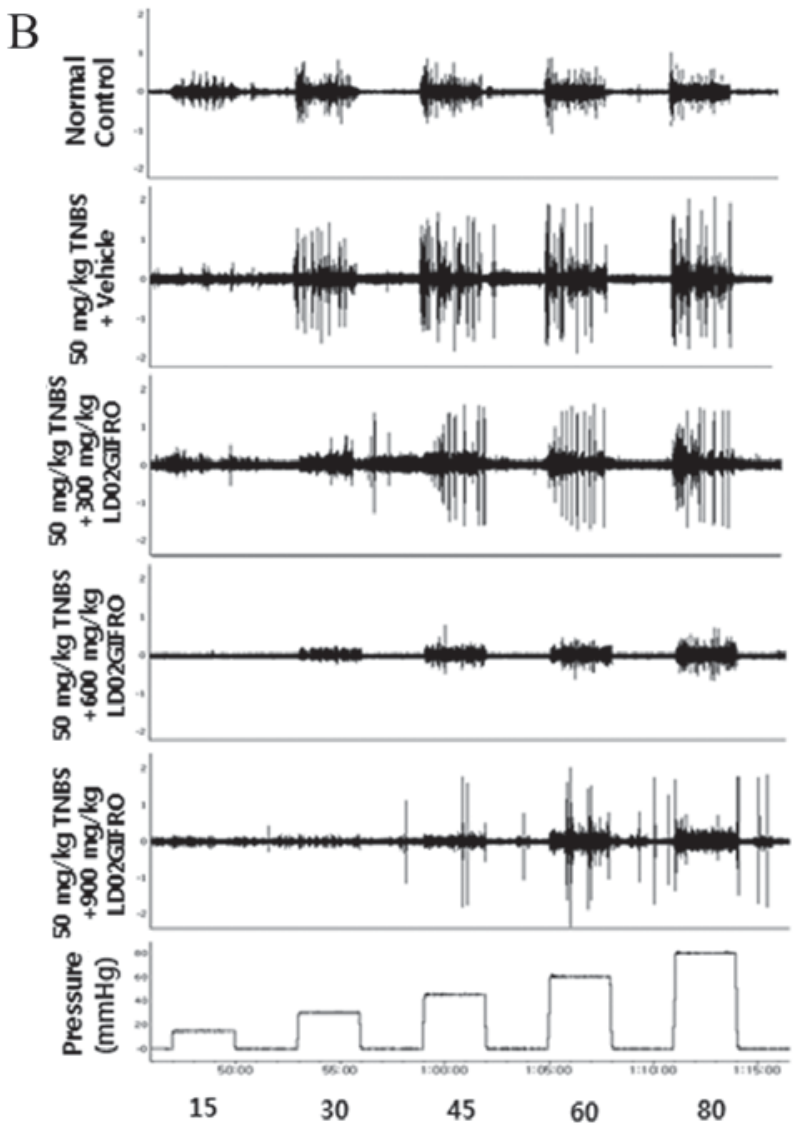

Figure 3. Effect of LD02GIFRO on VMR to CRD in rats with chronic hypersensitivity. (A) VMR to CRD in rats with TNBS-induced colonic hypersensitivity ( $\mathrm{n}=8$ ). (B) VMR to CRD represented as electromyography activity. (C) Effect of LD02GIFRO on VMR to CRD in rats with TNBS-induced colonic hypersensitivity $(\mathrm{n}=8)$. Values are presented as the mean \pm standard error of the mean. ${ }^{* *} \mathrm{P}<0.01 \mathrm{vs}$. normal control (vehicle). ${ }^{\# \#} \mathrm{P}<0.01 \mathrm{vs} .50 \mathrm{mg} / \mathrm{kg}$ TNBS plus vehicle. VMR, visceromotor response; CRD, colorectal distension; TNBS, trinitrobenzenesulfonic acid; PG, propylene glycol.

Several studies have demonstrated that 5 -HT has a pivotal role in the control of gastrointestinal motility and visceral sensations (39-41). Visceral hypersensitivity may be induced by abnormal afferent nervous function or central integration (42) and may be associated with digestive dysmotility $(43,44)$. Several visceral hypersensitivity models have been investigated, including that induced by acetic acid. In this model, mucosal inflammation was induced via mucosal exposure to acetic acid, inducing visceral hypersensitivity to rectal distension, which was suggested to be due to the higher degranulation rate of mast cells in the mucosa $(45,46)$. In addition, another study previously reported that postinflammatory visceral hypersensitivity was induced 30 days following infusion of TNBS (28). In the present study, LD02GIFRO was able to significantly ameliorate VMR to CRD in the acetic acid- and TNBS-induced hypersensitivity rat model.

$\mathrm{PF}$ exerts its prokinetic activity via influencing the $5-\mathrm{HT}_{3}$ and $5-\mathrm{HT}_{4}$ receptor mediated pathways $(47,48)$. In addition, $\mathrm{ZF}$, has been reported to ameliorate delayed GIT as an agonist of cholinergic nerves and the $5-\mathrm{HT}_{4}$ receptor $(22,23)$, which was confirmed in the present study using LD02GIFRO.

In conclusion, the results of the present study demonstrate that LD02GIFRO may have potential as an effective prokinetic agent capable of ameliorating gastrointestinal disorders and for an enhanced quality of life in patients with FGID.

\section{Acknowledgements}

The present study was supported by the Korean Health Industry Development Institute and the T2B Infrastructure Center for Digestive Disorders (grant no. HI15C0989).

\section{References}

1. Drossman DA: The functional gastrointestinal disorders and the rome III process. Gastroenterology 130: 1377-1390, 2006.

2. Hirako M, Kamiya T, Misu N, Kobayashi Y, Adachi H, Shikano M, Matsuhisa E and Kimura G: Impaired gastric motility and its relationship to gastrointestinal symptoms in patients with chronic renal failure. J Gastroenterol 40: 1116-1122, 2005.

3. Livingston EH and Passaro EP Jr: Postoperative ileus. Dig Dis Sci 35: 121-132, 1990.

4. Holte K and Kehlet H: Postoperative ileus: A preventable event. Br J Surg 87: 1480-1493, 2000.

5. Brix-Christensen V, Tønnesen E, Sanchez RG, Bilfinger TV and Stefano GB: Endogenous morphine levels increase following cardiac surgery as part of the antiinflammatory response? Int $\mathbf{J}$ Cardiol 62: 191-197, 1997

6. Taguchi A, Sharma N, Saleem RM, Sessler DI, Carpenter RL, Seyedsadr M and Kurz A: Selective postoperative inhibition of gastrointestinal opioid receptors. N Engl J Med 345: 935-940, 2001.

7. Holte K and Kehlet H: Postoperative ileus: Progress towards effective management. Drugs 62: 2603-2615, 2002.

8. Mattei P and Rombeau JL: Review of the pathophysiology and management of postoperative ileus. World J Surg 30: 1382-1391, 2006. 
9. Whitehead WE and Drescher VM: Perception of gastric contractions and Self-Control of gastric motility. Psychophysiology 17: $552-558,1980$

10. Kanazawa M, Hongo M and Fukudo S: Visceral hypersensitivity in irritable bowel syndrome. J Gastroenterol Hepatol 26 (Suppl 3) S119-S121, 2011.

11. Houghton LA, Calvert EL, Jackson NA, Cooper P and Whorwell PJ: Visceral sensation and emotion: A study using hypnosis. Gut 51: 701-704, 2002.

12. Coutinho SV, Plotsky PM, Sablad M, Miller JC, Zhou H, Bayati AI, McRoberts JA and Mayer EA: Neonatal maternal separation alters stress-induced responses to viscerosomatic nociceptive stimuli in rat. Am J Physiol Gastrointest Liver Physiol 282: G307-G316, 2002.

13. Longo WE and Vernava AM III: Prokinetic agents for lower gastrointestinal motility disorders. Dis Colon Rectum 36: 696-708, 1993

14. Drolet B, Rousseau G, Daleau P, Cardinal R and Turgeon J: Domperidone should not be considered a no-risk alternative to cisapride in the treatment of gastrointestinal motility disorders. Circulation 102: 1883-1885, 2000

15. Tack J, Camilleri M, Chang L, Chey WD, Galligan JJ, Lacy BE, Müller-Lissner S, Quigley EM, Schuurkes J, De Maeyer JH and Stanghellini V: Systematic review: Cardiovascular safety profile of 5-HT(4) agonists developed for gastrointestinal disorders. Aliment Pharmacol Ther 35: 745-767, 2012.

16. Hallerbäck B, Bommelaer G, Bredberg E, Campbell M, Hellblom M, Lauritsen K, Wienbeck M and Holmgren LL: Dose finding study of mosapride in functional dyspepsia: A placebo-controlled, randomized study. Aliment Pharmacol Ther 16: 959-967, 2002.

17. Holtmann G, Talley NJ, Liebregts T, Adam B and Parow C: A placebo-controlled trial of itopride in functional dyspepsia. $\mathrm{N}$ Engl J Med 354: 832-840, 2006

18. Kim DW, Shim JE, Paik HY, Song WO and Joung H: Nutritional intake of Korean population before and after adjusting for within-individual variations: 2001 Korean National Health and Nutrition Survey Data. Nutr Res Pract 5: 266-74, 2011.

19. Yi JM, Kim MS, Koo HN, Song BK, Yoo YH and Kim HM: Poncirus trifoliata fruit induces apoptosis in human promyelocytic leukemia cells. Clin Chim Acta 340: 179-185, 2004

20. Lee H, Seo E, Chung S and Shim C: Effect of an aqueous extract of dried immature fruit of poncirus trifoliata (L.) Raf on intestinal transit in rodents with experimental gastrointestinal motility dysfunctions. J Ethnopharmacol 102: 302-6, 2005.

21. Choi Y: The Korean Folklore Plants. Academybook, Seoul, South Korea, pp191-193, 1992.

22. Lee J, Chang K and Kim G: Composition and anti-inflammatory activities of Zanthoxylum schinifolium essential oil: Suppression of inducible nitric oxide synthase, cyclooxygenase-2, cytokines and cellular adhesion. J Sci Food Agric 89: 1762-1769, 2009.

23. Tokita Y, Yuzurihara M, Sakaguchi M, Satoh K and Kase Y: The pharmacological effects of daikenchuto, a traditional herbal medicine, on delayed gastrointestinal transit in rat postoperative ileus. J Pharmacol Sci 104: 303-310, 2007.

24. Shibata C, Sasaki I, Naito H, Ueno T and Matsuno S: The herbal medicine dai-kenchu-tou stimulates upper gut motility through cholinergic and 5-hydroxytryptamine 3 receptors in conscious dogs. Surgery 126: 918-924, 1999.

25. De Winter BY, Boeckxstaens GE, De Man JG, Moreels TG, Herman AG and Pelckmans PA: Differential effect of indomethacin and ketorolac on postoperative ileus in rats. Eur J Pharmacol 344: 71-76, 1998

26. Langlois A, Pascaud X, Junien JL, Dahl SG and Rivière PJ: Response heterogeneity of 5-HT3 receptor antagonists in a rat visceral hypersensitivity model. Eur J Pharmacol 318: 141-144, 1996.

27. Plourde V, St-Pierre S and Quirion R: Calcitonin gene-related peptide in viscerosensitive response to colorectal distension in rats. Am J Physiol 273: G191-G196, 1997.

28. Greenwood-Van Meerveld B, Venkova K, Hicks G, Dennis E and Crowell MD: Activation of peripheral 5-HT4 receptors attenuates colonic sensitivity to intraluminal distension. Neurogastroenterol Motil 18: 76-86, 2006.
29. Thompson Coon J and Ernst E: Systematic review: Herbal medicinal products for non-ulcer dyspepsia. Aliment Pharmacol Ther 16: 1689-1699, 2002.

30. Jin X, Shibata C, Naito H, Ueno T, Funayama Y, Fukushima K, Matsuno $\mathrm{S}$ and Sasaki I: Intraduodenal and intrajejunal administration of the herbal medicine, dai-kenchu-tou, stimulates small intestinal motility via cholinergic receptors in conscious dogs. Dig Dis Sci 46: 1171-1176, 2001.

31. Hayakawa T, Arakawa T, Kase Y, Akiyama S, Ishige A, Takeda S, Sasaki H, Uno H, Fukuda T, Higuchi K and Kobayashi K: Liu-Jun-Zi-Tang, a kampo medicine, promotes adaptive relaxation in isolated guinea pig stomachs. Drugs Exp Clin Res 25: 211-218, 1999.

32. Nakamura T, Sakai A, Isogami I, Noda K, Ueno K and Yano S: Abatement of morphine-induced slowing in gastrointestinal transit by Dai-kenchu-to, a traditional Japanese herbal medicine. Jpn J Pharmacol 88: 217-221, 2002.

33. Satoh K, Hayakawa T, Kase Y, Ishige A, Sasaki H, Nishikawa S, Kurosawa S, Yakabi K and Nakamura T: Mechanisms for contractile effect of Dai-kenchu-to in isolated guinea pig ileum. Dig Dis Sci 46: 250-256, 2001.

34. Kalff JC, Buchholz BM, Eskandari MK, Hierholzer C, Schraut WH, Simmons RL and Bauer AJ: Biphasic response to gut manipulation and temporal correlation of cellular infiltrates and muscle dysfunction in rat. Surgery 126: 498-509, 1999.

35. Kalff JC, Schraut WH, Simmons RL and Bauer AJ: Surgical manipulation of the gut elicits an intestinal muscularis inflammatory response resulting in postsurgical ileus. Ann Surg 228: 652-663, 1998

36. Panchal S, Müller-Schwefe P and Wurzelmann J: Opioid-induced bowel dysfunction: Prevalence, pathophysiology and burden. Int J Clin Pract 61: 1181-1187, 2007.

37. Grider JR and Makhlouf GM: Role of opioid neurons in the regulation of intestinal peristalsis. Am J Physiol 253: G226-G231, 1987.

38. Ruwart MJ, Klepper MS and Rush BD: Carbachol stimulation of gastrointestinal transit in the postoperative lleus rat. J Surg Res 26: 18-26, 1979.

39. Talley NJ: Serotoninergic neuroenteric modulators. Lancet 358: 2061-2068, 2001

40. Borman R and Burleigh D: Evidence for the involvement of a 5-HT4 receptor in the secretory response of human small intestine to 5-HT. Br J Pharmacol 110: 927-928, 1993.

41. Hillier K, Tam FS, Bunce K and Grossman C: Inhibition of motility induced by the activation of 5-HT1-like and 5-HT4-like receptor types in isolated human colon smooth muscle. British Journal of Pharmacology-Proceedings Supplement 112: 102P, 1994.

42. Sarnelli G, Vandenberghe J and Tack J: Visceral hypersensitivity in functional disorders of the upper gastrointestinal tract. Digestive and Liver Disease 36: 371-376, 2004.

43. Feinle-Bisset C, Vozzo R, Horowitz M and Talley NJ: Diet, food intake and disturbed physiology in the pathogenesis of symptoms in functional dyspepsia. Am J Gastroenterol 99: 170-181, 2004.

44. Nishiyama H, Mizuta Y, Isomoto H, Takeshima F, Omagari K, Miyahara Y, Murata I and Kohno S: Chronic visceral hypersensitivity renders defecation more susceptible to stress via a serotonergic pathway in rats. Dig Dis Sci 49: 763-769, 2004.

45. La JH, Kim TW, Sung TS, Kang JW, Kim HJ and Yang IS: Visceral hypersensitivity and altered colonic motility after subsidence of inflammation in a rat model of colitis. World J Gastroenterol 9: 2791-2795, 2003.

46. La JH, Kim TW, Sung TS, Kim HJ, Kim JY and Yang IS: Role of mucosal mast cells in visceral hypersensitivity in a rat model of irritable bowel syndrome. J Vet Sci 5: 319-324, 2004.

47. Shim WS, Back H, Jung SW, Kim JW, Jang Y, Lee B, Seo EK, Oh U and Shim CK: An aqueous extract of Poncirus fructus activates the prokinetic activity of 5-HT receptor subtype 4 without hERG interaction. J Ethnopharmacol 132: 328-333, 2010.

48. Kim BJ, Kim HW, Lee GS, Choi S, Jun JY, So I and Kim SJ: Poncirus trifoliate fruit modulates pacemaker activity in interstitial cells of Cajal from the murine small intestine. J Ethnopharmacol 149: 668-675, 2013. 